\title{
La cultura visual y la figura del espectador: de los inicios de la literatura sin contemplaciones
}

\section{Visual culture and the figure of the spectator: on the beginnings of literature without ceremony}

\author{
Àlex Matas Pons \\ Universidad de Barcelona \\ alexmatas@ub.edu
}

Recibido: 08-01-2013

Aceptado: 13-03-2014

\section{Resumen}

A lo largo del siglo XIX la cultura visual europea experimenta una radical transformación. El ciudadano puede llevar a cabo una amplia gama de inéditas experiencias sensoriales gracias a las nuevas prácticas del entretenimiento burgués y dispone de sofisticados artilugios tecnológicos para la reproducción de imágenes. La imagen alcanza una novedosa ubicuidad -desde lo artístico y lo lúdico hasta lo científico y lo mercantil- que exige un observador muy diferente al espectador clásico de la contemplación estética. Este artículo analiza, a partir de la crítica artística y la creación literaria de Baudelaire, cómo la modernidad literaria nace con esta nueva figura del espectador.

Palabras clave: Arte y literatura, cultura visual, modernidad literaria, Charles Baudelaire.

\begin{abstract}
Throughout the nineteenth century European visual culture undergoes a radical transformation. The citizen can perform a wide range of unknown sensory experi-
\end{abstract}


ences thanks to new practices of bourgeois entertainment and has sophisticated technological devices for the reproduction of images. The image reaches a new ubiquity -from the artistic and recreational to the scientific and the commercial- which requires an observer very different from the classic audience of the aesthetic contemplation. This article analyses, from the art criticism and the literary creation of Baudelaire, how aesthetic modernity is born with this new figure of the spectator.

Keywords: Art \& Literature, Visual culture, Literature of modernity, Charles Baudelaire.

\section{Modernidad y tecnologías de la representación}

Cuando se habla acerca de la modernidad literaria y se discute sobre quiénes fueron sus agentes principales, la preeminencia de Baudelaire es indiscutible. A menudo se enfatiza la trascendencia de los polémicos episodios que adornaron su carrera y se recuerda cómo su obra fue objeto de censura y él mismo sometido a juicio. El motivo del escándalo, en realidad, no fueron tanto las prostitutas, las drogas o el vino sobre los que hablan sus poemas como la incapacidad interpretativa de los lectores. Es decir, el hecho de que a mediados del siglo XIX resultaba incomprensible para los lectores el significado de su obra cuando se acercaban a ella desde las convenciones estéticas de aquel tiempo.

La misma incomprensión y persecución que padecieron Baudelaire y Flaubert es la que años más tarde padecería, en el ámbito de la pintura, Manet, cuando exhibe en el Salón de 1863 su Olympia. Los espectadores de la pintura de Manet tampoco entendieron qué significaba este retrato de una mujer desnuda, ya que no podían interpretarla como una nueva variación del tema de Venus. El escándalo lo motiva la orfandad hermenéutica del gusto burgués, es decir su absoluta incapacidad para comprender cualquier pintura que no reprodujera los motivos mitológicos de la tradición clásica o los ya vistos episodios históricos o bíblicos. ${ }^{1} \mathrm{Al}$ igual que había sucedido con Baudelaire, acusaron a Manet de torpeza técnica, pero la verdad es que Manet fue enormemente diestro cuando anonadó al espectador al ver éste representada su propia mirada en la tela. Manet lo había convertido en la intempestiva y frontal fuente de luz del cuadro, y había desestimado la iluminación lateral, suave y refinada, de Giorgione y de Tiziano, por ejemplo².

\footnotetext{
${ }^{1}$ El historiador del arte T.J. Clark analiza este episodio en su libro The Painting of Modern Life. in the Art of Manet and his Followers, Londres, Thames \& Hudson, 1984. También Félix de Azúa estudia este episodio en el capítulo "La ruptura del pacto" de su libro Cortocircuitos. Imágenes mudas, Madrid, Abada, 2004, pp 67-79.

2 Michel Foucault explicó en una conferencia pronunciada en Túnez en 1971 las diferentes técnicas pictóricas que empleó Manet. Su argumento orienta la línea de investigación propuesta en este artícu-
} 
Esta técnica de la iluminación, según explica Pierre Bourdieu en Las reglas del arte, hay que pensarla en el contexto de la batalla que se libraba por la conquista de la autonomía para el arte, pero no hay que olvidar que esta batalla la habían emprendido antes los escritores, como Baudelaire, tanto en sus obras de creación como en su crítica artística ${ }^{3}$. Todas las artes estaban comprometidas en un idéntico proceso que dependía fundamentalmente de cuál era el nuevo estatuto del observador. Y para ello, no sólo se trata de pensar en qué medida la propia experiencia del ciudadano en la novedosa y multitudinaria gran metrópolis implicó una nueva modalidad perceptiva, sino pensar también en todos aquellos inventos y experimentos en el ámbito de la representación visual que invadieron indistintamente tanto el espacio lúdico como el científico del público burgués: estereoscopios, fenakitiscopios, dioramas, panoramas, caleidoscopios, etc. Desde principios del siglo XIX se da ya una realidad socioeconómica, una serie de discursos filosóficos y unos procedimientos de subjetivación que no podían sino dislocar aquella antigua cultura visual heredada todavía de los códigos miméticos y del espacio en perspectiva 4 .

Roberto Calasso ha recordado recientemente en su libro La folie Baudelaire un episodio significativo que ilustra la importancia de esta interrelación entre escritores y pintores. Se trata del hallazgo en 1993 de cuatro daguerrotipos que habían quedado escondidos en el secrétaire de Ingres. Uno de ellos, realizado por DésiréFrançois Millet, reproduce un cuadro hoy desaparecido en el que el pintor había retratado a su primera esposa, Madeleine Chapelle. El daguerrotipo confirma que Ingres también contribuyó a esta conocida secuencia histórica de desnudos femeninos que iniciaron Giorgione y Tiziano y que culminaría con Manet, con su escandalosa Olympia. Lo más sorprendente es que el desnudo pintado por Ingres, aproximadamente diez años antes que la Olimpia, tampoco podría haber sido reconocido por parte del gusto burgués de la época como una nueva variación del tema de Venus, ni tan siquiera podría haberse visto reconfortado por la convencional coartada narrativa del género orientalista, que es lo que sucedería más adelante, en 1862, con la exhibición de El baño turco. El desnudo pintado por Ingres y hoy desapare-

\footnotetext{
lo, al sugerir que las telas del pintor francés persiguen el objetivo de cuestionar la autoridad del sujeto que mira mostrando los mecanismos que hacen posible el discurso visual y no disimulando sus estrategias. Foucault, M., La pintura de Manet, Barcelona, Alpha Decay, 2005.

3 Como es sabido, Pierre Bourdieu describe cómo la génesis del campo autónomo del arte no puede entenderse al margen de los otros agentes del campo del poder. En consecuencia, cuando se refiere a la técnica empleada por Manet escribe: "Manet invalida los fundamentos sociales del punto de vista fijo y absoluto del absolutismo artístico (como invalida la idea de un lugar privilegiado de la luz, a partir de entonces presente por doquier en la superficie de las cosas): instaura la pluralidad de los puntos de vista, que está escrita en la existencia misma de un campo (y cabe preguntarse si el abandono, cosa en la que se ha reparado a menudo, del punto de vista soberano, casi divino, en la propia escritura de la novela no está relacionado con la aparición, en el campo, de una pluralidad de perspectivas concurrentes)." Bourdieu, P., Las reglas del arte, Barcelona, Anagrama, 1997, p. 202.

4 Crary, J., Las técnicas del observador. Visión y modernidad en el siglo XIX, Murcia, Cendeac, 2008.
} 
cido, a pesar de ser obra de un pintor que se había formado en los talleres de David y que defendía siempre en público la obra de Rafael, buscaba eliminar nada menos que el espacio y procurar un encuentro sin coartadas entre el cuerpo femenino y "una mirada que es invadida por aquél"5.

El hecho de que hoy tengamos noticia de esta obra desaparecida gracias a un daguerrotipo puede que confirme, en un primer momento, el valor documental que posee la fotografía en general, pero sobre todo evidencia qué estrechas y también qué complejas fueron las relaciones que se dieron entre los diferentes métodos técnicos de reproducción de imágenes y la clásica tecnología artística en el París del siglo XIX. Por una lado, el episodio confirma que entre los nuevos métodos científicos, el daguerrotipo es aquel que, en particular, consigue fijar de manera permanente las imágenes de la camera obscura y prorroga por lo tanto el "espacio pictórico" renacentista y sus códigos miméticos. Además, al final logra divulgarlo de manera efectiva, puesto que el invento de Niepce y Daguerre fue adquirido inmediatamente por el Estado en 1839 y validado ante la Academia de Ciencias y Artes. Y con idéntica inmediatez, el invento también se popularizó gracias a la comercialización masiva que se hizo de él en la forma del retrato. Ambos factores se conjuraron para que fuera la faceta notarial y la de registro del invento la que prevaleciera en una prominente cultura tecnocientífica.

Pero, por otro lado, el episodio también sirve para llevar a cabo aquella consideración retrospectiva sobre la fotografía que Walter Benjamin demandaba y que precisamente estas óptimas condiciones para su "desarrollo permanentemente acelerado" que se han descrito habrían hecho imposible 6 . El descubrimiento del escondite donde se hallaba el daguerrotipo del desnudo pintado por Ingres invita a esta reconsideración, del mismo modo que el fotógrafo Joan Fontcuberta aprovecha el giro visual tomado por la actual cultura digital para reconsiderar el carácter notarial del daguerrotipo y nos advierte que en toda imagen fotográfica siempre ha habido manipulación de la realidad: junto a la faceta documental, dice Fontcuberta, existió desde siempre una faceta especulativa y ficcional, aunque luego con el tiempo fuera proscrita ${ }^{7}$. Las condiciones de difusión y comercialización son las que hicieron que el daguerrotipo explotara fundamentalmente aquellas virtudes que implicaban la continuidad de los antiguos códigos pictóricos "naturalistas" y hacían visible así la configuración de un sujeto, supuestamente "libre", heredado de la cámara oscura. Fue así como la fotografía llamó más la atención por su supuesta fidelidad y preci-

\footnotetext{
5 Escribe Roberto Calasso: "No hay ya el aireado paisaje de Giorgione; no existe la amplia sala de Tiziano en la que dos mujeres de fondo se afanan junto a un cajón; no hay ni siquiera el antro estrecho y oscuro en el que Olympia espera a sus clientes", La folie Baudelaire, Barcelona, Anagrama, 2012, p. 129.

6 Benjamin, W., Sobre la fotografia, Valencia, Pre-Textos, 2005, p.21.

7 Fontcuberta, J., La cámara de Pandora. La fotografi@ después de la fotografia, Barcelona, Gustavo Gili, 2010. Resulta útil la consulta del capítulo: «Ficciones documentales», pp. 102-109.
} 
sión que no por las trampas y los mecanismos de la ficción que había necesariamente que emplear para satisfacer el ansia descriptiva. Daguerre, por ejemplo, en el conocido daguerrotipo Vistas del Boulevard du Temple (1831), se vio obligado a contratar dos figurantes para evitar representar una calle desierta, puesto que las limitaciones tecnológicas impedían la fiel captación de los dinámicos carruajes y los paseantes que invadían las calles a todas horas.

Las Vistas que procuraban los daguerrotipos recordaban mucho las estáticas Vistas pictóricas de monumentos y arquitecturas, del mismo modo que los primeros daguerrotipistas pedían a su modelos que imitaran las convencionales poses del retrato pictórico. La comercialización masiva de estos retratos es una prueba de cómo los intereses políticos en emplear este nuevo invento para difundir la consigna del progreso y la democratización se aliaron también con las estrategias comerciales para "vender" de forma masiva el gusto burgués. Todo se aliaba para que el "espejo con memoria" prolongara todavía más la hegemonía de aquel espectador que había surgido con la camera obscura del Renacimiento y el discurso implícito que le acompañaba acerca de un sujeto de la percepción libre y soberano.

Pero al reconsiderar el daguerrotipo del desnudo pintado por Ingres, se observa que su inusitado erotismo se debe al modo en que explora precisamente las posibilidades del invento más alejadas de aquel discurso implícito y, a la vez, hegemónico: ni la representación simultánea de la doble postura de la modelo rememora la pose habitual de los desnudos de Giorgione o Tiziano ni la ausencia de espacio alrededor reconforta al espectador confirmándole en el abstracto punto de vista fijo, estable y monofocal, en que le había colocado esta misma tradición. Lo realmente relevante para el nacimiento de la modernidad estética fue que la nueva realidad social permitía la reproducción del arte como fotografía y no el conocido debate estético acerca de si la configuración de una fotografía era más o menos estética8.

El daguerrotipo no pudo explorar aquellas virtualidades que sí pudieron explotar el resto de las tecnologías de la representación contemporáneas, aunque estas sucumbieran finalmente ante el arrollador "desarrollo permanentemente acelerado" que padeció la fotografía, auspiciado por la alianza de la industria y el comercio burgués. Es en este sentido que hay que interpretar el rechazo de la fotografía por parte del mayor artífice y también teórico de la modernidad, Charles Baudelaire. Si rechaza la fotografía con tanta virulencia en sus críticas del Salón de 1859 es porque sabe que sólo se explotan del daguerrotipo aquellas facetas útiles para la ley del "Progreso"9; aquel "fanal oscuro", según lo había definido ya en su crónica de la

\footnotetext{
8 Benjamin 2005, op. cit. (nota 6) p. 48.

9 "En materia de pintura y de estatuaria, el Credo actual de las gentes de mundo es éste: «Creo que el arte es y no puede ser más que la reproducción exacta de la naturaleza. (...) De este modo, la industria que nos daría un resultado idéntico a la naturaleza sería el arte absoluto». Un Dios vengador ha atendido a los ruegos de esa multitud. Daguerre fue su Mesías. Y entonces se dice: «Puesto que la foto-
} 
Exposición Universal de 1885, aquella "linterna moderna [que] ensombrece todos los objetos del conocimiento".

\section{Arte y literatura: la écfrasis nerviosa}

Es evidente que no es el rechazo de un reaccionario ante cualquier nueva tecnología de la representación que se atreva a asomar la cabeza en la "sagrada" órbita de las artes ${ }^{10}$. Al contrario, Baudelaire ensalza las posibilidades que suponen para la imaginación artística los nuevos dispositivos científicos y la reorganización tecnológica del progreso modernizador en general. De hecho, según él, los mejores paisajistas son los aguafuertistas, como Méryon, los mejores paisajes son los artificiosos decorados teatrales y, finalmente, el mejor pintor de la "vida moderna" es el prácticamente desconocido Constantin Guys, descrito como una "caleidoscopio dotado de conciencia":

El enamorado de la vida universal entra en la multitud como un inmenso depósito de electricidad. También se le puede comparar, a él, a un espejo tan inmenso como la multitud; a un caleidoscopio dotado de conciencia que, a cada uno de sus movimientos representa la vida múltiple y la gracia moviente de todos los elementos de la vida11

El poeta francés aplaude, por lo tanto, la nueva percepción cinética que procuran los nuevos artilugios y, según él, las nuevas modalidades de la percepción ponen fin al espectador contemplativo y estético. Entre estas nuevas tecnologías destacan el estereoscopio, el artilugio más popular para el consumo de las imágenes fotográficas; los panoramas, que rompieron con el estatismo de la observación pictórica ya que el público giraba sobre sí mismo para abarcar un paisaje que se disponía a su alrededor en forma circular, y, en general, la mayoría de las nuevas prácticas del consumo burgués, que también implicaban un observador descentrado debido a la proliferante gama de experiencias ópticas y sensibles que acompañaba el consumo: los productos eran expuestos en los pasajes, estructuras de cristal y acero, y contemplados bajo las formas que proyectaba la iluminación artificial ${ }^{12}$. Baudelaire se percata de que la contemplación artística no puede pretender mantenerse aislada ante

grafía nos da todas las garantías deseables de exactitud (eso creen, ¡los insensatos!), el arte es la fotografía». A partir de ese momento, la sociedad inmunda se precipitó, como un solo Narciso, a contemplar su trivial imagen sobre el metal". Baudelaire, Ch., Salones y otros escritos sobre arte, Madrid, Visor, 1999, pp. 231-232.

10 Ibídem. P. 203. Para entender cuál fue el posicionamiento político de Baudelaire frente al progreso es muy recomendable leer el libro de Antoigne Compagnon, Los Antimodernos.

11 Ibídem, p. 359.

12 Además del libro clásico de Walter Benjamin, puede consultarse el libro de José Antonio Marinas, La fábula del bazar. Orígenes de la cultura del consumo, Madrid, Antonio Machado Libros, 2001. 
este nuevo contexto donde circulan con profusión imágenes, mercancías y toda clase de estímulos.

Todo ello lo ilustra un poema de Las flores del mal, "Sueño parisiense", dedicado precisamente a Constantin Guys, el "pintor de la vida moderna". Habla de un pintor que sueña con un "capricho" arquitectónico, un paisaje onírico ideal. Pero este pintor, "orgulloso de [su] genio", pronto constata que sus "prodigios" no son más que el ya poco convincente producto del uso artificial de la percepción: horrible novedad:/todo era visto, nada oído. Despierta del sueño al percatarse de la falsedad de aquella percepción, mágica pero descorporeizada, en la que el acto de visión había quedado cercenado del resto de los sentidos. Por algo Baudelaire, cuando definía al pintor de la vida moderna, lo comparaba con el caleidoscopio, capaz de captar la múltiple experiencia sensorial de "la vida misma y la gracia parpadeante de todos sus elementos".

Ya no es posible obviar el papel constitutivo del cuerpo en la aprehensión del mundo visible, y Baudelaire confirma esta evidencia histórica, brindada por los nuevos dispositivos y las nuevas prácticas de consumo, tanto en el "Sueño parisiense" como en el más programático y conocido de sus poemas: "Correspondencias". Cuando el hombre ingresa en la red de correspondencias, lo que percibe son "perfumes, sonidos y colores". Es decir, ingresa un cuerpo nervioso que percibe sinestésicamente la forma confusa de la apariencia de las cosas: "hay perfumes tan frescos como carnes de niños, /tan dulces cual oboes”. Aquí Baudelaire es fiel al espíritu científico de su época: si para los físicos los datos de la experiencia desmienten la posibilidad de un saber a priori, para Baudelaire los datos de la experiencia desmienten el orden de la Belleza Ideal. El arte asume, a partir de ahora, la misión de captar la "belleza contingente"13.

Baudelaire, con este acto totalmente inédito, valida el deslumbrante imaginario tecnológico y mercantil de su tiempo; legitima todo aquello que el férreo orden burgués de las artes está descartando porque no cabía en la preceptiva clásica heredada ni podía medirse según los códigos pictóricos vigentes: de hecho, el célebre

\footnotetext{
13 Véase el comentario que realiza Yves Bonnefoy del poema "Correspondencias": "À l'évidence première, qui montre que la Nature est un temple, un lieu où l'unité, le divin rayonnent de toutes parts, Baudelaire, en effet, en superpose une autre: les correspondances que l'«homme», l'homme d'aujourd'hui, peut appréhender sont entre des données de la perception. Auparavant, on vient de le voir, elles portaient sur des êtres. [...] Maintenant les «échos» de l'Un, ce sont-vaste déploiement du huitième vers- les couleurs, les parfums et les sons, c'est-à-dire de l'apparence: on verra la rose, mais comme de la couleur, du parfum, sans s'attacher immédiatement, intuitivement, à sa qualité cosmique, on verra du vert -pour reprendre une allusion du poème- avant d'avoir vu la prairie, on regardera le soleil, mais sans pouvoir le fixer, comme Nerval s'étonnait déjà que l'on eût pu le faire, car l'impression passe désormais par le corps- plutôt don con regardera toutes les couleurs, tous les tons du soleil couchant, richesse mais dans laquelle «se fige» le sang de ce que Nerval appelait «la vie». Bonnefoy, Y., Sous le signe de Baudelaire, Gallimard, Paris, 2011, p. 92.
} 
poema "Correspondencias" parece estar motivado por la visita que realizó el poeta a la Exposición Universal de 1855. Ante uno de los jarrones chinos que formaban parte de la Exposición, Baudelaire afirma:

¿Qué haría, qué diría un Winckelman moderno? [...] ¿Qué diría, qué escribiría,-vuelvo a repetirlo, frente a fenómenos insólitos, uno de esos modernos "profesores jurados" de estética? [...] El insensato doctrinario de lo Bello disparataría, sin duda; encerrado en la obcecadora fortaleza de su sistema, blasfemaría de la vida y de la naturaleza, y su fanatismo griego, italiano o parisino, le persuadiría para prohibir a ese pueblo insolente el gozar, el soñar o el pensar mediante otros procedimientos que no fueran los suyos propios; - iciencia emborronada de tinta, gusto bastardo, más bárbara que los bárbaros, que ha olvidado el color del cielo, la forma vegetal, el movimiento y el olor de la animalidad, y cuyos dedos crispados, paralizados por la pluma, ya no pueden correr con agilidad sobre el inmenso teclado de las "correspondencias"!14

En las exposiciones Universales, además de la maquinaria y toda clase de herramientas industriales, se exhibía una amplia gama de exóticos productos coloniales que también deslumbraba a la multitud de visitantes. Baudelaire parece darse cuenta de la persuasión que ejercen estos objetos; del impacto que ejercen con su fuerza icónica sobre la fantasía y la imaginación del burgués. No son simples e inocentes objetos, apreciados tan solo por su valor de uso, sino objetos ambiguos sin finalidad clara sobre los que se hace converger el tipo de interés que tradicionalmente estaba reservado para la obra de arte. Esta nueva realidad, según el poeta, por fuerza afectaría a la obra de arte, y se equivocan quienes pretenden en vano que siga desempeñando su función social tradicional o invistiéndose de su autoridad tradicional15.

Pero Baudelaire ya había prestado antes atención a la nueva y determinante comunión entre tecnología y mercancía en "Moral del juguete", un artículo escrito en 1853, donde evoca la visita que realizó siendo niño a casa de la señora Pankoucke. Explica que gracias a esta aventura infantil pudo experimentar por primera vez el "extraordinario y verdaderamente fantástico" placer de estar en una estancia llena de juguetes, donde el "techo desaparecería bajo la floración de juguetes que colgaban como maravillosas estalactitas" 16 . Desde entonces, resultaba ya imposible pasar frente a los escaparates de las tiendas de juguetes y no detenerse ante ellos para "recorrer con la mirada la inextricable muchedumbre de sus formas extrañas y de sus colores dispares". Resulta imposible resistir la atracción que despiertan unos objetos pensados para la improductiva actividad del juego; es decir,

\footnotetext{
14 Baudelaire 1999, op. cit. (nota 9), pp. 199-200.

15 Agamben, Giorgio, «Baudelaire o la mercancía absoluta» en Estancias. La palabra y el fantasma en la cultura occidental, Valencia, Pre-Textos, 2001. pp. 85-92.

16 Baudelaire 1999, op. cit. (nota 9), pp. 191.
} 
unos ambiguos e inquietantes objetos que son deseables por ellos mismos, sin servir de condición para otra cosa que no sea el simple goce17. No es casualidad que algunas de las más célebres Aguafuertes porteñas de Roberto Arlt -quien siempre confesó su admiración por Baudelaire y que, al igual que el poeta francés, validó en el orden de las artes todo aquello ilegítimo que provenía del orden tecnológico y mercantil18- estén dedicados a los niños-hombre, contra los que Baudelaire ya nos previno en su artículo, porque "usan sus juguetes" y ruegan "no tocar a sus amiguitos". Estos niños-hombre de los que habla Roberto Arlt "parecen estar embutidos en la negrura de un traje curialesco" y "tienen algo de sótano de una carbonería complicado con la afectuosidad de un verdugo en decadencia"; lo mismo que aquellas "nenas", de las que también habla el escritor argentino, que sólo juegan con la muñeca el día que llegaban las visitas"19. Unos y otras han dejado de apreciar los juguetes por lo que en realidad son, unos objetos fascinantes que cumplen solamente con la función intransitiva del jugar, y los han convertido en objetos útiles, asignándoles funciones impropias que en realidad prefiguran el universo de las funciones adultas.

Los niños-hombre serían, según explica Roland Barthes en una de sus Mitologías, "pequeños propietarios sin inquietudes" 20 . Los juguetes producidos por la ideología burguesa convierten a los niños en usuarios, pero jamás en creadores o inventores. Son juguetes producidos para mostrarle al niño un enorme catálogo con todo aquello que ha dejado de asombrar a los adultos -la guerra, la burocracia o la fealdad- y lo preparan precisamente para usar este mundo, pero jamás para inventar nada. Baudelaire alertaba contra estos niños-hombre, porque él sobre todo apreciaba la transcendencia artística de aquella primera "tendencia metafísica" que veía en los niños cuando estaban frente a sus juguetes, cuando el niño "da vueltas y más vueltas a su juguete" preguntándose "¿pero dónde está el alma?”. Es sin duda el "carácter de fetiche" de los juguetes lo que le permite al poeta establecer una analogía entre la relación que mantiene el niño con sus muñecos o artilugios y la que mantiene el artista con los objetos.

En la "Moral del juguete", los juguetes científicos permiten a Baudelaire fundir en una misma argumentación su objetivo de validar lo tecnológico y lo mercantil frente al orden de lo artístico. Artilugios pensados para la reproducción de imágenes como el estereoscopio y el fenakitiscopio son, según el autor de Las flores del

\footnotetext{
17 Pardo, J. L., «¿Qué quiere un niño?», en Nunca fue tan hermosa la basura, Barcelona, Galaxia Gutenberg, 2010, pp. 41-56.

18 Véanse los libros de Beatriz Sarlo La modernidad periférica: Buenos Aires 1920 y 1930, Buenos Aires, Nueva Visión, 1988 y La imaginación técnica. Sueños modernos de la cultura argentina, Buenos Aires, Nueva Visión, 1992

19 Arlt, R., "Los chicos que nacieron viejos" y "Taller de compostura de muñecas", en Obras. Tomo II, Buenos Aires, Losada, pp. 33-39.

${ }^{20}$ Barthes, R., "Juguetes” en Mitologías, México. D.F., Siglo XXI, pp. 51-53.
} 
mal, los que mejor pueden desarrollar en "el cerebro del niño el gusto por los efectos maravillosos y sorprendentes" 21 . Ante la convergencia de las nuevas tecnologías y las nuevas funciones económicas y simbólicas de los objetos y las imágenes, parece inevitable que emerja un nuevo sujeto de la percepción incompatible con el espectador contemplativo. Un sujeto de la percepción para quien la coherencia unificada y homogénea de los modelos clásicos de la visión se ha vuelto ya imposible, y cuya atención requiere de una fragmentación del campo visual. Ya no es tan sólo que el arte no pueda pretender una suerte de aislamiento estético imposible, sino que él es también, necesariamente, un elemento fundamental en esta reconfiguración de la percepción que tiene lugar a mediados del siglo XIX, puesto que las imágenes artísticas al fin y al cabo cobran sentido en un contexto en que la imagen en general goza de una nueva ubicuidad en la ciudad, donde la distracción y la novedad constituyen la experiencia de la percepción ${ }^{22}$.

\section{Baudelaire cierra la ventana}

Como hemos visto, Baudelaire disiente de aquellos que creen que el aislamiento estético de la pintura es una solución por la que procurar preeminencia social a lo artístico y, por el contrario, defiende que hay que celebrar y aprovechar esta nueva realidad en la que las imágenes artísticas se confunden con las innumerables imágenes que son consumidas de forma masiva en las múltiples prácticas lúdicas de la percepción. Así se lee en sus críticas a los Salones y en sus visitas a las Exposiciones Universales, pero también en su labor poética. La lírica de Baudelaire responde también al empeño desmitificador del poeta; empeño según el cual lo Verdadero y lo Bello en poesía y en pintura deben admitir la condición de lo contingente y lo temporal. Y la mejor muestra de todo ello es su escritura poética en prosa, El spleen de París, donde opta por el género que más puede alejarle de aquella figuración del poeta que había prevalecido durante tanto tiempo en la tradición occidental, la que lo presentaba como imagen en la tierra del Dios soberano, omnisciente $^{23}$. La prosa poética querría dar cuenta de la percepción dislocada, siempre en movimiento y sometida a desequilibrios y distracciones, del nuevo sujeto de la percepción. Un sujeto nervioso que habita entre las multitudes urbanas. Son conocidas las palabras que dirige Baudelaire a su amigo Arsène Houssaye en la carta que prologa la edición de Los pequeños poemas en prosa:

\footnotetext{
${ }^{21}$ Baudelaire, Ch. 1999, op. cit. (nota 9) pp. 194.

22 Jonathan Crary en su libro clásico Suspensiones de la percepción explica cómo esta reconfiguración de la experiencia de la percepción tenderá a un régimen disciplinario en la formación colectiva de la atención mediante mecanismos, sobre todo, de repetición.
}

23 Bonnefoy, 2011, op. cit. (nota 12) p. 113. 
¿Quién de nosotros no ha soñado, en sus días más ambiciosos, con el milagro de una prosa poética y musical, aunque sin ritmo ni rima, lo suficientemente flexible y contrastada como para adaptarse a los movimientos líricos del alma, a las ondulaciones del ensueño, a los sobresaltos de la conciencia?24

Necesitaba una nueva voz lírica, desprovista de toda grandilocuencia y de toda Gran Esperanza, que se contentara con ser mera tentativa de aproximación a una realidad, la del poeta, que en lo fundamental no difería tanto de la realidad de su fraternal "Hypocrite lecteur". Para ello, Baudelaire tenía que cerrar la ventana que había abierto L.B. Alberti en 1453, cuando publicó en Florencia su tratado Della Pittura e inauguró una revolución en la mirada al caracterizar la pintura como una «ventana abierta». Baudelaire, por su parte, escribe un poema en prosa titulado "Las ventanas": "Quien mira una ventana desde fuera a través de una ventana abierta, no ve nunca tantas cosas como el que mira una ventana cerrada». Esta ventana -abierta tiempo atrás, cuando el artista dejó su condición de artesano y accedió a la nueva condición de creador, en una nueva rivalidad directa de Dios- era, para Alberti, la metáfora del método de la perspectiva. Comparó la superficie de la imagen con el cristal transparente, tras el cual se desplegaría con profundidad la representación de un espacio tridimensional, homogéneo y coherente. Así quedó fundada también una concepción revolucionaria de la subjetividad 25 .

Baudelaire, por su parte pensó, que esta ventana debía cerrarse ya, como también lo creyeron, por ejemplo, Désiré-François Millet, aquel daguerrotipista que reprodujo el desnudo que había pintado Ingres de su primera esposa, o Manet, cuando pintó y expuso su Olympia. También lo pensó, poco después, Monet, cuando pinta en 1873 el Boulevard des Capucines y muestra una ciudad donde los clásicos figurantes desaparecen para convertirse en manchas que evocan la presencia de la multitud y el movimiento de las calles: la imagen no es la del cristal transparente, sino la de una ventana cerrada por cuyo cristal resbalan unas gotas de humedad que hacen irrelevante la idea de la profundidad. Todos ellos protagonizan un período de la historia de la literatura y del arte en el que ya no es viable aquella visión que había inventado L.B. Alberti; una visión puramente geométrica, es decir, hecha de puntos y líneas, obtenida por un sujeto que había sido reducido a un único órgano: el ojo.

\footnotetext{
24 Baudelaire, Ch., Obra poética completa, Madrid, Akal, 2003, p. 363.

$25 \mathrm{La}$ importancia del método de la perspectiva para la historia del arte y del pensamiento estético occidental fue resumida por Panofsky en su libro Idea del siguiente modo: "La concepción artística del Renacimiento se opone así a la medieval, extrayendo en cierto modo al objeto del mundo representativo interior del sujeto y asignándole un lugar en un «mundo exterior» sólidamente fundamentado, de tal modo que establece (como la práctica artística la "perspectiva») una distancia que al mismo tiempo objetiva al objeto y personaliza al sujeto". Idea, Madrid, Cátedra, pp. 49-50. Véase también el libro del mismo Panofsky, La perspectiva como forma simbólica y el libro de Hubert Damisch, L'origine de la perspective, Paris, Flammarion, 1987.
} 